\title{
PERSPECTIVAS FUTURAS DE LA RETÓRICA EN SU CONEXIÓN CON LA HERMENÉUTICA
}

\author{
Mauricio BEUCHOT \\ UNAM, México
}

\section{Planteamiento}

En este trabajo me interesa hablar de la argumentación retórica (entendida al modo de Perelman) y su conexión con la hermenéutica. Creo que el estudio de estas relaciones ha de marcar el futuro de ambas disciplinas. En efecto, la retórica y la hermenéutica siempre han estado muy vinculadas. Podemos aludir a la polémica entre el sentido literal y el sentido alegórico en la patrística, y mencionar a San Agustín como uno de los más clarividentes respecto de ello, y señalar la estrecha vinculación de la retórica con la hermenéutica, ya que no se la veía sólo como la disciplina para encodificar, expresar o emitir mensajes, sino también como teniendo la otra función, de decodificar, recibir o interpretar mensajes.

Es necesario profundizar en esta conexión de la retórica con la hermenéutica, y además con una hermenéutica analógica; ${ }^{1}$ para eso veremos el carácter analógico de la retórica misma. Eso la mostrará como el mejor instrumento argumentativo de la hermenéutica. Concebimos la retórica como Perelman, abarcando la tópica o dialéctica además de lo que propiamente concebimos como retórica. Mas, en todo caso, siempre es una recuperación del antiguo ideal de una argumentación viva. Por eso se trata de una retórica que implica el diálogo, como en la tópica o dialéctica.

1 Cf. M. BeuCHOT, Tratado de hermenéutica analógica, México: Universidad Nacional Autónoma de México (UNAM), 1997. 


\section{Retórica y hermenéutica}

En efecto, una de las funciones de la retórica: la de interpretar, fue la que quedó como propia de la hermenéutica en la actualidad. Por eso es conveniente recuperar para la hermenéutica la otra función de la retórica: la de emitir de manera persuasiva. Y esto tiene dos aspectos, uno lógico de argumentación y otro psicológico de seducción. La hermenéutica necesita poder argumentar, para así convencer de una interpretación de manera racional o razonablemente válida, y no sólo por la seducción poética o manipulación de los sentimientos (psicagogia); pero tiene además necesidad de introducir elementos elocutivos y hasta poéticos, para reforzar la argumentación con la seducción poética. Pero no se reduce a la seducción poético-psicagógica, como tampoco se reduce a la argumentación lógica. Está en medio de ellas, como un análogo, casi como un oxímoron. Por eso será bueno examinar las relaciones que puede tener la retórica con la hermenéutica, y, sobre todo, vistas desde la perspectiva de la analogicidad (esto es, una retórica analógica con una hermenéutica analógica).

De hecho, una de las formas que ha tenido la hermenéutica en la historia ha sido la retórica. Pero también ha sido la retórica uno de los ámbitos que más fuertemente ha vivido la lucha de lo unívoco y lo equívoco en su seno. En algunos momentos se ha ganado para ella la analogicidad. Pero hay que plantearla de manera más decidida. El mostrar la retórica como discurso analógico ayudará a ver más claramente la misma naturaleza analógica de la retoricidad y de la hermenéutica, y por ende mostrará más a las claras la atingencia de una hermenéutica analógica, que es la hermenéutica que venimos buscando y planteando. Esa hermenéutica analógica podrá servirse de dicha retórica como de un método argumentativo para su discusión y su diálogo. No se rechaza la conexión de la retórica con la lógica, a través de la noción de tópico, aledaña a la noción de regla de inferencia o de matriz argumental; pero sí se indica una argumentación que no exige, como la lógica apodíctica, un andamiaje axiomático, sino una que se conformará a veces con la lógica tópica o de lo plausible, y a veces incluso sólo con lo verosímil de la retórica. Es una retórica en el sentido de Perelman, esto es, un método argumentativo que conjunta la tópica y la retórica propiamente dicha.

En todo caso, la analogía se encuentra de muchas formas en la retórica. Es uno de sus lugares favoritos. Está presente en la comparación o semejanza; 
tembién lo está en el tópico del exemplum, del paradigma; éste dispara el razonamiento o argumento por analogía, en el que se hace una inducción restringida, de lo particular a lo particular, que, sin embargo, apunta y contiene a lo universal; igualmente se encuentra en el razonamiento de los efectos a las causas, esto es, en la metonimia; y también se encuentra en la metáfora, a saber, en la translación o sustitución que implica una interacción entre el sentido literal y el trópico. Sin embargo, creo que la analogía se encuentra más allá, de manera más profunda. No solamente compara, no solamente busca semejanzas; sobre todo marca diferencias, señala límites; y, en este sentido, apunta hacia la realidad. Está, por ello, en el corazón de la retórica, es la conciencia de que sólo se puede hablar aproximadamente de las cosas, esto es, lleva a una ontología peculiar, la de lo verosímil, a la vez humilde y suficiente. En el fondo, es el núcleo de toda ontología.

Ciertamente el discurso analógico tiene mucho de modestia o de humildad, no llega a la cientificidad de lo unívico. Pero tal vez por eso es tan propia de la retórica. Tal vez por haber relegado la retórica, la modernidad endureció su metafísica y su cientificismo. Y viene muy bien atender a ella, para obtener una filosofía con un rostro más humano. Mas, al ver la presencia tan importante de la analogía en la retórica, vemos asimismo la presencia de la analogía en la ontología, precisamente una ontología que se desprende de la retórica misma, que surge de ella a la vez que la funda. Trataré de hacer ver cómo surge esta ontología de la analogicidad de la retórica. Partiré de algunas consideraciones sobre la condición de la retórica; pasaré luego a esa presencia fuerte de la analogicidad que es la metáfora; insistiré en que también se da la presencia de la metonimia en la analogía y en la retórica; de ahí avanzaré, en seguida, a la posibilidad que se abre de una nueva ontología que acompañe a la retórica, una ontología analógica; y accederé, finalmente, a algunas condiciones filosóficas que tiene la retórica para poder existir, las cuales, como se verá, están del lado de una racionalidad proporcional o analógica.

\section{La metáfora como modalidad de la analogía que vive dentro de la retórica}

Si nos fijamos bien, encontramos que la retórica de Aristóteles tiene tres sectores: (i) una teoría de la argumentación, que vincula a la oratoria con la lógica y, a través de ella, con la filosofía, (ii) una teoría de la elocución y (iii) 
una teoría de la composición del discurso. La retórica posterior se quedó en la elocución, y ésta en la teoría de los tropos. Con ello se la desconectaba de la dialéctica, o lógica, y de la filosofía. A primera vista, la filosofía no puede vincularse con la retórica, porque se aboca a la verdad, y no puede regular el poder. Pero creo que sí, y que esto se da a través de su elaboración de una teoría de la verosimilitud, que muestre los límites de la retórica misma y que la defienda de sus propios excesos, a saber: la adulación, la seducción y la amenaza, todas las cuales son violencia teórica o discursiva. El poder de la elocuencia y la lógica de lo verosímil constituían el núcleo de la retórica aristotélica.

Una presencia de la analogía, además del ejemplo inductivo esto es, del paradigma, o modelo o ícono, es la metáfora. La metáfora es un recurso de la retórica, pero también lo es de la poética. Difiere según la función que adquiere en cada una. En la primera funciona para la persuasión; en la segunda, para la purificación (kátharsis). En ella se conjuntan la prueba persuasiva y las artes miméticas, y eso es lo que justifica ultimadamente a la metáfora. La mímesis o imitación nunca es copia servil, sino reescritura creativa; no es unívoca, es análoga. Aristóteles entiende la metáfora como traslación de significados, esto es, define la metáfora con otra metáfora, una de movimiento. Eso indica que sólo se puede tratar de la metáfora metafóricamente ${ }^{2}$. Predomina la diferencia, más que la semejanza. Es lo que olvidó Derrida en su tratamiento de la metáfora, al estudiarla en el Estagirita.

Mas, aun cuando Aristóteles quiere ver la metáfora como la traslación de un nombre de una cosa a otra, sobre todo por su analogicidad, no puede quedarse al nivel del nombre o de la palabra; su mismo análisis lo hace ir más allá. Tiene que ir hasta la función de ésta en una semántica del discurso y hasta su lugar en una teoría de la interpretación de la obra. (De hecho, no se halla en él una distinción tajante entre sentido propio y sentido figurado.) En efecto, la traslación requiere por lo menos afectar a dos palabras, exige una estructura de géneros y especies, un juego de relaciones ordenadas, para violarlo ${ }^{3}$. Hay una transgresión de algo prohibido: lo que Ryle llama cerror categorial", que era una cosa a evitar. Pero viola o destruye un orden sólo para crear otro, el error categorial es sólo el reverso de una lógica del descubrimiento. Por eso la metáfora no puede afectar sólo a la palabra, sino al enunciado y al mismo dis-

2 Cf. P. Ricoeur, La metáfora viva, Madrid: Eds. Europa, 1980, pág. 30.

3 Cf. ibid., pág. 35. 
curso. Y, como la metáfora tiene cierto carácter enigmático, la verdad que le compete no es tanto una sustitución como una tensión. Por eso Aristóteles no reduce la metáfora a mero ornato del lenguaje.

Ricoeur opone en la metáfora una teoría de la sustitución y otra de la interacción. Es la oposición entre una semiótica de la palabra y una de la frase y la obra. La metáfora no es sólo sustitución, es una interacción entre el sentido literal y el metafórico, entre la referencia literal y la metafórica, y, por lo mismo, entre la verdad literal y la metafórica. Hay una referencia doble: primaria y secundaria. Una tensión en el seno de la semejanza. No se funden los opuestos, están en tensión. (La misma analogía es una tensión.) Ricoeur aprovecha la noción de «er como» de Wittegenstein. Ver una cosa como otra, aunque no lo sea. El error categorial abre la posibilidad de una nueva visión ${ }^{4}$. La referencia según Goodman tiene un doble modo: descripción y ejemplificación, y la metáfora está más en la línea de esta última. Es iverdadera” en la medida en que es apropiada, en la medida en que añade la conveniencia a la novedad, la evidencia a la sorpresa ${ }^{5}$. Tiene además un carácter heurístico: la metáfora inventan, en el doble sentido de la palabra latina, de crear lo que descubre y descubrir lo que crea.

Es una tensión entre el (es" y el "no es», hay en ella algo paradójico. La verdad metafórica participa de esa paradoja: «a paradoja consiste en que no hay otra forma de hacer justicia a la noción de verdad metafórica sino icluyendo el aspecto crítico del "no es" (literalmente) en la vehemencia ontológica del "es" (metafórico). En esto, la tesis no hace más que sacar la consecuencia más extrema de la teoría de la tensión» ${ }^{6}$. Así, aunque el sentido literal y el metafórico son distintos, tiene que haber alguna intersección entre ellos, como la hay entre la filosofía y la poesía. De este modo la poesía puede cuestionar y enriquecer la noción filosófica de verdad y la de realidad. Aquí me parece ver que la metafísica tiene la capacidad de actuar en dos ámbitos de referencia: uno familiar y otro nuevo.

La lección que encuentro en la exposición de la metáfora hecha por Ricoeur es que la retórica vive de la metaforicidad de la verdad y su discurso. Pero yo quisiera universalizar más lo que ha dicho Ricoeur, y de otra manera. La metáfora es sólo una de las formas de la analogía. Me parece que hay que

\footnotetext{
Cf. ibid, pág. 310.

Cf. ibid, pág. 321.

Ibid., pág. 343.
} 
hacer entrar en la retórica (y en la discursividad en general) no sólo la metaforicidad, sino la analogicidad entera de la verdad y de lo razonable. No solamente la analogía metafórica, sino la de atribución y la de proporcionalidad, la analogía metonímica. En todas esas clases de la analogía se da la misma tensión o tensionalidad que se da en la metáfora, pero de modo diferente. Con menos oposición entre lo literal y lo metafórico, pero no con menor rendimiento en la aplicación. Como un reconocimiento de que la verdad es analógica, la verosimilitud que se maneja en la retórica (a diferencia de la verdad de la lógica) y lo razonable que se maneja en la retórica (a diferencia de la racionalidad más mecánica de la lógica) hacen que no se pueda quedar en una versión de la verdad como lo literal, sino tirando a lo figurado. Pero no siempre tendrá analogía metafórica, metaforicidad; a veces tendrá metonimia, a veces sinécdoque, o alguna de las otras figuras o tropos. E inclusive no renunciará a toda literalidad. Se trata de una verdad y una racionalidad trópicas: la de la verosimilitud y la de lo razonable. Pero tiene eso y más, una gama de posibilidades que, sin perder el rigor de lo unívoco, la hace acercarse a la vorágine de lo equívoco, aunque sin perderse en ella, sorteándola.

\section{Retórica y ontología}

A veces se ha creído que la retórica, o la retoricidad, de la filosofia reciente implica un renunciar a la ontología, a la metafísica. No es verdad. La retórica conduce a la metafísica. Más aún, hay una metafísica para la retórica, hay una ontología que se aviene con ella. Ciertamente no una metafisica dura y pretenciosa, sino una metafísica que sea consciente de la dificultad de argumentar metafisicamente. De hecho, la argumentación retórica es la única que queda a los enunciados metafísicos, sobre todo a los más de principio. Son los principios los que no se pueden demostrar ya, pues toda demostración deductiva implicaría partir de otros principios, con lo cual se daría una progresión infinita.

Que la retórica conduce a una ontología lo atestigua el que Perelmann y Olbrechts-Tytheca hablen de ciertas formas de la argumentación retórica que son «conexiones que fundan la estructura de lo real" ${ }^{7}$. Ellas son los ejemplos,

7 C. Perelman, L. Olbrechts-TyTeCA, Traité de l'argumentation. La nouvelle rhétorique, Bruxelles: Université de Bruxelles, 1970 (3a. ed.), pág. 470. 
los modelos y la analogía. Esos recursos hacen que los oyentes puedan participar de la verdad que se les propone, «hacer la verdad». Pero, además, la retórica conduce a un tipo de ontología particular y determinado, y creemos que de tipo muy distinto del que toca a la lógica univocista.

Es curioso darse cuenta de que la ontología que concuerda con la retórica ha de ser una ontología basada en lo verosímil, que hace creíbles sus enunciados, y con ello basta. No hay la pretensión de la perfecta comprensión ni del perfecto acuerdo. Tampoco hay el peligro de caer en lo disparatado. Es como el conocimiento de lo metafórico, que oscila entre la parte de literalidad y la parte de figuratividad o tropo que toda metáfora contiene. Si se queda en lo literal, no se ha captado la riqueza cognoscitiva que allí se encierra; si se queda en lo figurado, se pierden los límites de la interpretación y se puede extraer cualquier conocimiento, cualquier comprensión, cualquier sentido. Es, también, el sentido del exemplum, paradigma o ícono, muestra lo universal en su propia individualidad y fragmentariedad.

Esa metafísica de la retórica se presenta, pues, como su límite, como metafísica limítrofe, liminar. Es lo que evitará que el sentido se pierda, es lo que hará que el sentido se case o copule con su referencia, para que engendren la analogía de la verdad. Esto es, para que la retórica no pierda su verosimilitud, para que haya un criterio de lo verosímil mismo. Una ontología de lo verosímil, una ontología verosímil ella misma, que ancla lo verosímil a un mundo verosímil, un mundo posible, y nos ofrece los límites de éste. La referencia es lo que embona con el objeto, es la tierra nutricia de la que sale y a la que vuelve; es la posibilidad de anclarse en algo y no perderse en la alocada corriente de los signos producidos por el hombre. Pero vamos hacia la referencia a través del sentido. El sentido, que corre el peligro de armar sólo un juego, un juego de coherencias sin conexión con la realidad. El positivismo lógico distinguió y separó unas verdades de razón y unas verdades de hecho. Las primeras eran puro sentido idealista, las segundas pura referencialidad empírica. $Y$ cada grupo iba por su lado, sin poder tocarse jamás. La retórica tiene una vocación para evitar esa dicotomía, esa dualidad tan marcada, con su recurso a lo verosímil. La verosimilitud es la que hace concordar el sentido con la referencia, nos ayuda a tocar suelo con un poco de guía o insinuación de la verdad. Por eso nos hace discurrir desde el sentido hacia la referencia, con pocas razones, pero persuasivas, y nos coloca en el camino de la ontología, de la mano de la convicción intersubjetiva. 
La ontología que va con la retórica es como ella, un saber que se discute y se va construyendo incesantemente. Como la llamaba Aristóteles, da ciencia buscada" (he zetoumene episteme, he epizetoumene episteme) ${ }^{8}$, mejor le estaría el decir: «a ciencia siempre buscada», porque siempre está encontrándose y reencontrándose, pues trata de tocar ese misterio que es la realidad misma, el ser, y abrir su enigma. Y eso solamente podrá ser parcial, pero suficiente. Es un saber analógico, consciente de que mucho se queda en el equívoco, y de que no se puede alcanzar en ello univocidad; pero que no renuncia a hacer un esfuerzo por balbucir el ser, el sentido y la referencia. Ontología retorizada, a la que sólo le queda el recurso argumentativo de la retoricidad de lo que se acepta en parte por el logos y en parte por el pathos, con una argumentación indirecta, ad hominem, y aun diríamos ad totum hominem, porque argumenta a todo el hombre, intelecto y afecto, a la comprensión y al gozo ${ }^{9}$. Como inferencia formal, muy limitada; pero como inferencia trascendental, muy rica. Más que en la sintaxis y la semántica, se asienta en la pragmática, en la performatividad que se gestaba en la ilocutividad misma. Como lo diría Peirce, es la trascendentalización de la semiótica y al mismo tiempo la semiotización de la filosofía trascendental, tal vez más esto último, con lo cual se da cabida a una ontología que no podía aceptar la trascendentalización sola y que ahora, a través de la semiotización, se despliega sutil. Es la retórica como semiótica. Pero, al dar el paso del sentido a la referencia, la retórica prmite pasar de la trascendentalización a la semiotización, y da lugar a la referencia realista más allá del puro sentido idealista. Se llega inevitablemente a una ontología.

En efecto, el significado pragmático, como lo hacen ver Austin y Searle, no se queda en el puro sentido, no puede, sino que accede a la referencia; son los actos de habla, precisamente, los que conjuntan a un sentido con su referencia $^{10}$. Y si la retórica vive del significado pragmático, más allá de la sintaxis y la semántica, se ve obligada a tocar con sus manos la referencia, o al menos a

8 Cf. ARistoteles, Metafisica, B, 2, 996 b3 y K, 1, 1059a35. Ver M. BeUCHOT, "Aristóteles, o la fundación filosófica de la retórica" en VARIOs, Aristóteles, Mendoza (Argentina): Universidad Nacional de Cuyo, 1998, págs. 34-39.

9 Como es sabido, Perelman dice que se trata, más bien, de un argumento ad humanitatem, esto es, a todo hombre, a la comunidad de los hombres razonables. Esto parece difícil de conseguirse, a saber, el consenso de todos ellos, pero no deja de manifestar un deseo de universalización muy interesante.

10 J. L. Austin, «Cómo hablar, en el mismo, Ensayos Filosóficos, Madrid: Eds. de la Revista de Occidente, 1975, págs. 134-135; J. SEARLE, Actos de habla, Madrid: Eds. Cátedra, 1990, pág. 37. 
apuntar hacia ella, y en todo caso a pensar en una ontología que se exige a partir de su noción de significado. Hay una onto-pragmática que se desarrolla en el mismo seno de la retórica y aflora hacia la ontología y la metafísica explícitas. Pero ellas ya son otro asunto. Con todo, no ha de tenerse miedo a que la retórica nos conduzca a la ontología, ya que la va como modelando y centrando en sus pretensiones, dándole proporción.

\section{Argumentación analógica}

La argumentación requiere, pues, un giro analógico, en el sentido de que se pueda laborar en los argumentos con expresiones que no alcanzan la plena univocidad, pero que tampoco incurren en una equivocidad completa. Lo analógico tiene una sede muy conveniente en lo verosímil, característica peculiar de la argumentación retórica. Es la analogía con lo verdadero. El mismo carácter dialógico de la retórica postula la analogicidad del conocimiento, ya que en el diálogo es donde más se dificulta la obtención de la univocidad y el riesgo del equívoco. También el supuesto antropológico que subyace a la retórica es el de un ser humano que conoce y se expresa en las lindes de lo analógico, un pensamiento preponderantemente análogo. Y la ontología que le subyace es una ontología que acepta que lo evidente puede tratarse como verosímil. Pero que, en todo caso, la retórica tiene también una base de verdad, un supuesto ontológico. Su metafísica subyacente.

Es precisamente la verdad metafísica la que puede proporcionar un criterio para medir la verosimilitud de la argumentación retórica. Si bien es cierto que estamos hablando de una metafísica que procura una fundamentación moderada, sólo analógica (como son los principios del ser), y que aporta un punto de partida que no es totalmente claro y distinto, sino sujeto al discernimiento movedizo y a veces en el claroscuro, no menos cierto es también que esta metafísica, manifestada por la retórica, y que la acompaña siempre de modo implícito, nos da una base suficiente para establecer la fundación o fundamentación de la verosimilitud. Es como una marca, un límite, algo que da criterio, aunque no sea de una manera absoluta e inconmovible. Se trata de la alusión a la referencia, pues no nos quedamos en el solo sentido. El sentido es alusivo a la referencia, no elusivo de ella; dirige hacia un mundo, nos hace asomarnos a él más allá del mismo marco conceptual desde el que miramos, pues nos coloca en el límite de éste, y lo trasponemos con la creatividad para encontrar algo 
nuevo. Es la transgresión del límite epistemológico, que amenaza con encerrarnos en el relativismo sin salida. Nos asomamos desde los marcos conceptuales como desde marcos de ventanas cerradas, que se resisten a ser abiertas, pero que podemos abrir con lo que les vamos añadiendo desde una creatividad apegada a las condiciones de posibilidad de lo real mismo. Traspasamos los límites del lenguaje, de la cultura, del marco conceptual, como lo decía Strawson: no hace falta brincar esos límites, basta con poder pensarlos. Así daremos, colocados en el límite, encabalgados en la frontera con el ser, una inferencia trascendental, fundada en la realidad, que nos hará pensar las condiciones de posibilidad de lo real y al mismo tiempo ver los objetos en las mismas interpretaciones. Tal es el intento de Peirce de cancelar la dicotomía entre fenómeno y noúmeno. El noúmeno se nos da en el fenómeno, y el fenómeno nos remite indefectiblemente al noúmeno, como su signo, como su representamen. En el fenómeno tenemos una intuición intelectiva del noúmeno, la abstracción a partir de lo sensible nos abre camino a la metafísica.

Además de la intuición, siempre se ha postulado el raciocinio, el discurso, la argumentación. Algunos han perdido la esperanza en la argumentación, y se quiere que no haya la posibilidad de ofrecer argumentos para apoyar nuestras intuiciones. Pero una polémica de intuiciones nadie la gana. Tiene que buscarse alguna forma de argumentación si no queremos hundirnos en la falta de criterios, de principios y de pruebas. Y esa forma es la de una argumentación situada, concreta, contextuada ${ }^{11}$. Sin embargo, es una argumentación que señala lo universal, tiene una validez suficiente como para asegurar la verosimilitud de los enclaves de la ontología que estamos demarcando. Con la argumentación verosímil, algunas veces como dice el propio Aristóteles se alcanzará la verdad misma. Esto nos muestra el poder veritativo de la verosimilitud, y el poder universalizador de la analogía, que desentraña esa universalidad en el mismo individuo, en lo concreto que es donde se encuentra realizada.

\section{Otros aspectos hermenéutico-analógicos de la retórica}

Conviene, además, resaltar algunas cosas que creo que acompañan, desde el ámbito de la filosoffa, a la retórica. Son cosas que confirman su carácter ana-

11 Inclusive tiene que ser oportuna y conveniente, como un fármaco. Cf. A. LOPEZ, Eire, Esencia y objeto de la retórica, México: UNAM, 1996, págs. 24 ss. 
lógico, y que hacen ver más profundamente la conexión de la hermenéutica con la retórica, sobre todo una hermenéutica analógica con una retórica analógica como el método amplio de las ciencias humanas o humanidades (incluyendo en ellas la filosofía). Algo así como el lado filosófico de la retórica misma. En sus aspectos lógico y epistemológico, sobresale el carácter de verosimilitud, no de verdad plena, del conocimiento que da pues no se le exige más y la persuasión que brinda, en el dominio de lo lógico y afectivo. Es donde veo que la retórica tiene una condición híbrida, analógica.

Ese país de lo analógico pertenece al imperio de la retórica; ella tiene que afanarse por conducir a las mentes de los participantes del diálogo a través de los mares procelosos de lo no completamente claro, y por en medio de los tupidos boscajes de lo que no queda plenamente distinto. Tiene que aclarar y distinguir, argumentar para persuadir de lo que no es del todo aceptable ni del todo rechazable, sino intermedio; ni tautológico ni contradictorio, contingente. Dentro del ámbito de lo contingente es donde más se presenta la analogía, la analogicidad de pensamiento, porque encierra la posibilidad de dar asentimiento a lo que se logre presentar como intermedio entre lo evidente ( $y$ aun lo verdadero plausible) y lo rechazable, a saber, lo verosímil.

\section{El giro analógico de la argumentación}

Al giro lingüístico de la filosofía ha seguido (o ha acompañado) un giro pragmático y, a éste, un giro retórico. Pues en verdad se acompañan muy de cerca. Efectivamente, tal parece que asistimos a una vuelta del trivium latino y medieval: gramática, lógica o dialéctica y retórica. Pero, más que al regreso de la gramática y la lógica, al de la retórica. Esto puede tener como explicación la desconfianza que ha surgido recientemente respecto de la racionalidad moderna, sobre todo positivista o cientificista, que exacerbó la lógica y la quiso aplicar de manera desmedida a todo. Pero también se explica por el auge de la postmodernidad, que ha puesto como metodología filosófica universal a la hermenéutica, con la cual la retórica tiene mucho en común, como lo han señalado Gadamer, Ricoeur y Vattimo ${ }^{12}$.

12 Cf. H. G. GADAMER, «Rhétorique, herméneutique et critique de l'idéologie» en Archives de Philosophie, 34 (1971), págs. 211 ss.; P. RicoEUR, \&hétorique-Poétique-Herméneutique», en 
Por otro lado, podemos decir que la retórica es la búsqueda de una discursividad analógica, si por analogía entendemos lo que está intermedio entre lo unívoco y lo equívoco, esto es, la significación y la predicación de lo que es en parte igual y en parte diferente, predominando la diferencia. La construcción positivista tira a la univocidad, la desconstrucción postmoderna tira a la equivocidad. Yo quisiera proponer la re-construcción analógica, un giro analógico en la argumentación en nuestro caso presente, en la retórica. Así, frente a una lógica unívoca y una disgregación equívoca, añado algo distinto, que es la discursividad analógica. Nótese que es un tercero: addo tertium!, como se decía en el debate medieval, pues en verdad la analogía es terceridad, como podríamos decir ahora en el lenguaje de Peirce. Centraré en la retórica esa terceridad o analogía que propongo, aunque ya de por sí la retórica es emblema de analogicidad. Ante la desconfianza de la verdad lógica o necesaria, esto es, de la racionalidad analítica, se ha notado un sesgo muy marcado hacia la verdad sólo plausible, esto es, la racionalidad tópica, tanto dialéctica como retórica ( $\mathrm{y}$ a veces hasta poética). Pero se ha ido con mucho extremismo, y hace falta un centramiento o equilibrio. Más allá de la lógica de la univocidad, está la de la analogía, en la dialéctica y la retórica. En lugar de quedarse en la negación o disolución de los contrarios, une y sitúa las opiniones o tesis contrarias unas respecto de las otras. La lógica de la univocidad o de la identidad destruye las opiniones que se enfrentan, la lógica de la analogía busca integrarlas en lo que es compatible, sin perder de vista sus diferencias. La dialéctica (y lo mismo hace la retórica) desemboca muchas veces en la construcción de razones que, sobrepasando los elementos antagónicos, los reconcilian considerándolos como momentos de una verdad superior ${ }^{13}$.

La retórica supone un razonamiento contextuado, en contexto. Su argumentación no opera en el vacío, toma en cuenta el auditorio y le da argumentos que esté dispuesto a aceptar. No es la argumentación analítica o lógicodeductiva, sino una argumentación circunstanciada. No es, por tanto, una

M. MEYER (ed.), De la métaphysique à la rhétorique, Bruxelles: Eds. de l'Université de Bruxelles, 1986, pág. 146 ss.; G. VATTIMO, «erdad, retórica, hermenéutican en Revista de Estética (Buenos Aires), n. 2 (1984). Ver también M. BEUCHOT, Hermenéutica y retórica en Hans Georg Gadamer, en Semiosis (Univ. Veracruzana), 18 (1987), págs. 141-148; y el mismo, (Reflexiones sobre la retórica desde la hermenéutican en Acta Poetica (UNAM), 14-15 (1993-1994), págs.
295-307.

13 Cf. C. Brualre, La dialectique, Paris: PUF, 1985, págs. 38 ss. 
argumentación unívoca, válida para todos por igual. Tampoco puede ser una argumentación equívoca, completamente relativista, casi diríamos que en función de cada quién. Más bien se trata de una argumentación analógica, con cierta pérdida y desencuentro, pero con la suficiente igualdad persuasiva como para llegar (aun con diferente grado de fuerza) a todos o a la mayoría de los que están conformando el auditorio ${ }^{14}$.

Una de las cosas en las que se ve aplicada la analogía o analogicidad dentro de la retórica es la amplificación oratoria. La amplificación es algo muy propio y característico de la elocuencia: es el discurso amplificado para persuadir. No hay auténtica retórica sin amplificación, como no hay auténtica poética sin metáfora. Pero la amplificación ha de conocer sus límites. Siempre se avisaba en las retóricas, en la parte preceptiva, que había que tener cuidado con el uso de las amplificaciones, tropos y figuras, ya que fácilmente se derrumbaba la construcción y se caía en el ridículo. Pues bien, los límites de la amplificación los da la razón (aplicada en la prudencia). En efecto, la retórica tiene una parte racional o de lo razonable, que es toda una teoría de la argumentación. Y otra parte para mover los afectos, que en Aristóteles era la psicagogía y en Fray Luis de Granada era precisamente la amplificación ${ }^{15}$. La amplificación es la conmoción de los sentimientos o de las pasiones. Pero, si no se tiene ponderación en ello, se incurre en lo extremadamente sentimental, en lo cursi. Se necesita un equilibrio oscilante, prudencial, analógico.

Es cierto que no es conveniente encerrarse en una retórica puramente racional, como lo quería Pascal, quien decía que el mejor ejemplo de retórica

14 Sobre esto ha tratado mucho Perelman. Cf. M. BEUCHOT, \&ilosofía y retórica en Chaïm Perelman: el auditorio universal razonable» en Éndoxa (UNED, Madrid), 3 (1994), págs. 301-316. Pero yo trato de ir más allá de lo que ha dejado Perelman, que parece demasiado univocista en su exigencia de oyentes ideales, ya que, de una manera kantiana y como idea reguladora, dice que, en definitiva, el filósofo es un orador que se dirige, como a un público, al hombre razonable en sí, lo cual es una mera abstracción. Más bien hay que contar con que los hombres razonables se dan en una oscilación analógica. La misma idealización tiene que ajustarse poco a poco a la realidad, para que pueda ser útil.

15 Cf. Fr. L. DE GRANADA, Libri sex ecclesiasticae rhetoricae, Pampilone: apud Petrum Iosephum ab Ezquerro, 1751, págs. 103 ss. Ver también M. BEUCHOT, «Algunos aspectos de la retórica en Fray Luis de Granada», en La Ciencia Tomista (Salamanca, España), 113 (1986), págs. 127-143; el mismo, «ray Luis de Granada: la retórica y el sentimientoß en Morphé (Univ. Aut. de Puebla), 7 (1992), págs. 131-139; y el mismo, aRetórica y filosofía en Fray Luis de Granadas en A. Garcfa del Moral, U. Alonso del Campo (comps.), Fray Luis de Granada. Su obra y su tiempo, Granada: Universidad de Granada, 1993, vol. I, págs. 489-500. 
serían los Elementos de Euclides. Para él, sólo puede el hombre conocer el mecanismo de la razón, pues el mecanismo del corazón es tan misterioso que sólo puede concerlo en sus resortes más íntimos su creador, Dios ${ }^{16}$. Una retórica unívoca se iría por la sola razón. Una retórica equívoca se iría por el solo sentimiento. Una retórica analógica se iría por el equilibrio de la razón y el sentimiento. Mas no un equilibrio o moderación aguados o tibios, sino más del lado del sentimiento que de la pura razón. No se olvide que en la analogía predomina la equivocidad sobre la univocidad (no en balde los maestros escolásticos la colocaban como una de las especies de la equivocidad), la cual en este caso es el sentimiento. Por eso la retórica tiene que dar predominio al sentimiento sobre la razón.

Pero esto se da en una tensión fructífera. Así como antes se hablaba de una dialéctica positiva (la de Bachelard) y de una dialéctica negativa (la de Adorno), así puede hablarse de una analogía positiva y de una analogía negativa, según que se acerque más al intento de decir o al de no decir, de callar (esto es, según su oscilación entre lo unívoco y lo equívoco). Mas también puede hablarse de una analogía sintética o sintetizadora, que integra elementos sin confusión, sino conservando su diferencia propia. $Y$ es esta analogicidad integradora la que deseo atribuir a la retórica. Es el encuentro entre el concepto y el afecto, y no puro concepto o razón ni puro afecto o sentimiento. Se enriquece con las dos dimensiones, dándole a cada una su lugar y sus límites. Ciertamente predomina el sentimiento, pero también dentro de los límites justos que le competen, que lo hacen no sólo efectivo sino también respetuoso de esa participación de la verdad que toca a la retórica y que se llama verosimilitud, el ámbito de lo verosímil, que el hombre necesita para su hambre de veridicción, de veracidad.

\section{Retórica y diálogo}

La analogía se encuentra en el diálogo. Requiere del diálogo para darse, además de que el diálogo resulta siempre analógico, aproximativo, huidizo. La analogía se busca y se establece o se precisa en comunidad, en el acuerdo y en

16 Cf. Blas PASCAL, Del espíritu geométrico y del arte de persuadirı trad. e introd. de M. BeUCHOT, en Tetraktys (Universidad Iberoamericana, México), n. 3 (1987), págs. 9-19. 
la concordia de los que dialogan. Los interlocutores necesitan compartir y poner en común muchas de sus riquezas: experiencias, ideas, interpretaciones, hipótesis y argumentaciones. Pone en juego la capacidad de los interlocutores de sugerir, de provocar y de persuadir. Cuenta con nuestras búsquedas e investigaciones comunitarias. $Y$ todo eso exige una situación dialógica.

Por otra parte, la situación dialógica en la retórica adquiere varios y diversos matices. A veces hay diálogo retórico pleno, otras veces resulta incompleto. Pues no siempre se puede dar cabida a todo lo que quiere decir el otro. Hay interacciones retóricas en las que interviene un interlocutor y luego otro; pero, dada la amplificación, se corre el risego de que predomine el monólogo. Por eso resulta necesario moderar de manera prudencial el ornato. Dejar fuerza a la argumentación, la cual se condensa en el entimema; pero también dejar cierto predominio a la expresión ornamentada, casi monológica, como un poema en el que uno se extiende morosamente.

En la tradición grecolatina se llegaba a decir que la dialéctica implicaba el diálogo, mientras que la retórica no siempre. En la retórica forense vemos que sí lo implica, aunque, por ejemplo, en otras piezas retóricas, como en la homilía, no se da propiamente. No se da propiamente, es decir, de manera biunívoca; pero sí se da de manera analógica, ya que el predicador debe plantearse adecuadas preguntas retóricas, y responderlas convincentemente, para dejar satisfechos a sus oyentes. Con eso se recupera, al menos un tanto, la dialogicidad de fondo que se esconde en todo género de la retórica.

Por otra parte, el diálogo implica supuestos psicológicos y hasta éticos. En el lado psicológico (y sociológico) pide la igualdad y la libertad. Que se sienta la igualdad y que haya la libertad suficiente para enfrentarse al otro. En el lado ético, la exigencia de veracidad, de modo que la oratoria no se convierta en sofística. Es sabido que la retórica tuvo un gran auge con los sofistas, pero también lo es que Aristóteles la rescató de sus manos, para acercarla a una clara exigencia de veracidad y de justicia ${ }^{17}$. Estos supuestos psicológicos y éticos de la retórica son supuestos analógicos. También tiene algunos supuestos antropológico-filosóficos muy importantes, que veremos a continuación.

17 Recordemos las pretensiones de veracidad y de validez, que aparecen en Habermas, pero que no son de él ni son nuevas. Se remontan hasta los rhetores griegos y son sistematizadas por Cicerón y Quintiliano. Cf. M. Beuchot, Cicerón: entre el arte y la habilidad natural de la retórican, en Noua Tellus (UNAM), 13 (1995), págs. 59-69. 


\section{Supuestos antropológicos de la retórica}

A la actitud que concede relevancia a la retórica subyace una antropología filosófica, una filosofia del hombre. Es una concepción del ser humano como sujeto y objeto de lo razonable. Concepción del hombre que da en él un lugar muy importante al diálogo (por más que a veces no pueda ser completo). Además, no es sólo lugar de lo razonable, sino también de lo emotivo; no sólo de lo verdadero y de lo probable, sino también de lo verosímil; y no sólo de lo argumentable, sino de lo ornamental. Hay una alusión a la imaginación que no se da en la dialéctica, con lo cual se acerca a la poética.

Se trata de una concepción del hombre como ser analógico, como análogon. El análogon, el híbrido, es el que participa de varios mundos. El hombre participa del mundo de la razón y también del mundo del corazón. No es un ser monolítico o unívoco, sino alguien que se realiza en diálogo con los demás, en el proceso de compartir lo suyo con los otros. Es que la dialogicidad y la analogicidad van de la mano, se posibilitan y se promueven la una a la otra. Entendido como análogon, el hombre es un microcosmos y un confín, es decir, es una mixtura de las cosas del cosmos; pero también es el límite entre ellas, y al mismo tiempo es horizonte. Límite en el que se fusionan varios horizontes, el hombre entendido como microcosmos tiene lugar en la retórica a título de exigencia; es un oyente exigente, juez de las partes, y hay que acceder a su conciencia y a su emoción para convencerlo, esto es, para persuadirlo y seducirlo a la vez, con la verdad, con la bondad y la belleza: con el argumento que golpea (contundente) y con el ornato que acaricia (deleitable). Es el hombre entendido como susceptible de motivación, sujeto y objeto de la retórica.

Además, de una manera si se quiere sociológica, la retórica supone igualdad y libertad. Sólo puede darse en cierta relación igual, de iguales, de democracia, no de tiranía. El tirano no escucha razones, sólo ordena, sin argumentar. Impone por la violencia, por el poder. Se persuade a los que son libres, a los que son libres de pensar lo opuesto y que pueden mover su voluntad hacia otra cosa. Ciertamente no basta la igualdad de fuerza física o jurídica, pues se puede hacer violencia retórica, mediante la sofística. Pero por eso se exige la veracidad y la ausencia de intenciones torcidas; es la igualdad discursiva (que incluso puede llevar no sólo a no querer engañar al otro, sino a promoverlo y ayudarlo). Hay una intención y un interés de quien persuade. Sobre todo al estatuir $\mathbf{o}$ aplicar leyes. 


\section{La intencionalidad en la retórica}

En la retórica es importantísima la intencionalidad del orador, ya que ella se necesita para que pueda haber argumentación y para que pueda haber persuasión. Suelen suponerse oyentes ideales para el orador-hablante. Hay que tener cautela. Otra vez, sólo proporcionalmente puede pensarse en esto; de manera diferenciada, ponderada, equilibrada, analógica. Oyentes ideales serían aquellos que pudieran captar adecuadamente la intencionalidad del hablante, o el significado del hablante, esto es, del orador. Pero sabemos que la idealización sólo se hace para disminuirla hasta que dé con la realidad. Hay una tensión analógica, una interacción prudencial, en la que se combina lo que de conocimiento por connaturalidad y lo que de conocimiento por inferencia pueda darse entre hablantes y oyentes que no son ideales.

La retórica ha tenido como propia la elocución ${ }^{18}$, y eso parece referirse a lo que ahora se llama lo ilocucionario y lo perlocucionario. Lo máximamente perlocutivo sería la Palabra de Dios: diciendo, hace. Pero la performatividad de la palabra humana depende de su ilocutividad, de su fuerza ilocutiva. Entre los griegos tenía aún un resabio de carga mágica. Magia de la palabra. Era fármaco, terapia y catarsis. Cuando no se tiene que persuadir, se embellece el discurso; y no por solo gusto poético, sino también por responder a la condición retórica. Esto se ve en varios aspectos del género epidíctico, como en la homilía; no necesita persuadir de la religión o de la moral, porque los destinatarios ya están persuadidos; entonces sólo necesita embellecer, para incrementar el amor y llevar a la virtud.

\section{Lo estructural de la retórica}

La proliferación de esquemas formales de la gramática, retórica y poética ha abultado tanto las disciplinas del lenguaje, que ahora da la impresión de que lo han inundado todo. Los niveles morfosintácticos y léxicosemánticos se han desbordado y desparramado. Además de la proliferación de instrumentos de análisis, la de los textos a analizar produce ahora la sensación de que todo ocurre, sea natural o cultural, dentro de un grande y poderoso ámbito intratextual

18 Cf. Fr. L. DE GRANADA, op. cit., págs. 209 ss. 
de un inmenso texto, de modo que todo es texto, da la sensación de que todo son relaciones inter- e intra-textuales, la sensación de que no hay realidad.

Esto hace percibir una situación perturbadora de agobio, de estar ahogados por los textos, por la textualidad, de no poder salir a ningún lugar, a nada que no sea texto, que no haya sido ya escrito y hollado por el hombre. El hombre es ya ur escritor infinito, cuyas obras, cuyos signos se le han soltado, se le han escapado.

Pero eso no siempre es útil, llega a ser desconcertante, y debe ser encerrado en sus justos límites. Esos justos límites se verán al acotar la metaforicidad del lenguaje, la capacidad metafórica de la retórica misma. Lo haré entreverando, anacrónicamente, a Aristóteles con Ricoeur. A ello paso en seguida.

\section{La retórica y la analogía}

Dada la dimensión simbólica, además de la literal, que alcanza la filosofía en su trabajo hermenéutico-pragmático, se requiere la analogía, que va más allá de la univocidad de lo literal, pero sin caer en la equivocidad de la polisemia desenfrenada e irrecuperable. Si en el lenguaje, como lo ha hecho notar Gadamer, y según lo ha recalcado Ricoeur, hay cierta ambigüedad y metaforicidad, en todo lenguaje luchan esos elementos de la metáfora que son la verdad literal y la verdad metafórica, o simbólica. Por ello se hace necesaria una hermenéutica que vaya junto con la retórica, y una retórica y una hermenéutica pues son sólo las dos caras de la misma moneda, la comunicación, con su encodificación y decodificación que ponga en ejercicio esas fuerzas; y sólo podrá hacerlo una hermenéutica analógica, $\mathfrak{i}$ cerradamente unívoca ni desbocadamente equívoca.

La retórica es el reverso de la hermenéutica, y una y otra guardan isomorfismo entre sí; tienen isomorfía indudable, pues una sirve para emitir y la otra para recibir, una tiene el papel de encodificar y la otra de decodificar, y los mismos recursos tradicionalmente se usan para las dos cosas, singularmente la metáfora. Pero la metáfora es sólo una de los modos de la analogía, la cual abarca además la atribución y la porporcionalidad propia además de la proporcionalidad impropia, que es la propia metaforicidad. Por eso, para un diálogo rico y fructífero, y para una argumentación amplia pero exigente, se requiere de la analogía, ella es la pauta para plantear la hermenéutica y la pragmática, $\mathrm{y}$, consiguientemente, la retórica. 
Así, una retórica analógica acorde a una hermenéutica y una pragmática también analógicas puede abrir el camino hacia una ontología igualmente analógica. De esta manera ya no se puede pensar que toda retórica cierra la puerta para la ontología, porque sería encerrarla en el solipsismo del monólogo, y, por lo tanto, ya no será diálogo filosófico, sino sólo monólogo compartido. La retórica analógica hace tocar fondo en una ontología analógica, que vive de la tensión metafórica y proporcional entre el sentido literal y el simbólico ${ }^{19}$. Un sentido enriquecido, que supla la pérdida y el empobrecimiento natural de nuestras transacciones comunicativas.

Sobre todo cuando se trata de diálogo entre sistemas diferentes, no al interior del mismo; pues en ese caso se da una situación parecida al diálogo entre culturas, o entre tradiciones, aborígenes distintos y casi prisioneros, como estamos, de nuestros propios sistemas. Pues bien, es en ese momento cuando menos se puede recurrir a la argumentación directa y deductiva, y hay que acudir a la indirecta y retórica. Y es cuando la analogía, la analogicidad, podrá acercarnos, de una manera dia-filosófica (que no meta-filosófica, pretenciosa e impositiva), de modo tal que la analogía produzca un ámbito de encuentro, en el que se pueda dialogar fructíferamente, porque hay la posibilidad de aprender algo del otro sistema y modificar al menos un poco el nuestro. Con la voluntad de recuperar y conciliar lo más que se pueda, en lugar de rechazar y destrozar los pensamientos.

\section{Resultados}

La retórica, entonces, padece analogicidad, como la padece y la tiene la discursividad que aflora al nivel semiótico de la pragmática (o de la hermenéutica). La retórica es juego de espejos, en el que la realidad se refleja en su propio reflejo, que es el lenguaje; y no se puede evitar tener la sensación de que el lenguaje nos la transforma, la transfigura. Pero nos la hace verosímil, nos la da aceptable, y eso basta. Ello es suficiente para retornar al polvo, al brillante polvo de aquellos lodos en los que tuvo su origen. Ontología retorizada, o retó-

19 Cf. P. Rucoeur, Rhétorique - Poétique - Herméneutique en M. MEYER (ed.), De la métaphysique à la rhétorique, ed. cit., pág. 146. También podría decirse, aplicando un quiasmo al título que Meyer ha dado a su coompilación, De la rhétorique à la métaphysique. La retórica nos abre a una ontología o metafísica acorde con la hermenéutica y con la poética. 
rica ontologizada, u ontología retórica, o retórica ontológica. Michel Meyer intitulaba su libro De la metafisica a la retórica. Podríamos llamar a nuestro capítulo y a nuestro empeño De la retórica a la metafisica. Es el movimiento de vuelta, del quiasmo retórico. Es tiempo de volver al origen, perdidos como estuvimos en el proceloso mar del lenguaje, azotados por el alto y peligroso oleaje de los discursos. Aturdidos por su sonido, o cautivados por el dulce canto de las sirenas de la sofística. Ahora podemos tocar el puerto de la ontología. Todo ello por la mediación que efectúa ese conocimiento limítrofe (de límites y llevado al límite, entre el lenguaje y el ser) que es la analogía.

$\mathrm{Y}$, en síntesis y conclusión de este capítulo, la filosofía necesita ser más atenta a las limitaciones del diálogo que puede darse entre los sistemas que abarca. Esa limitación hace que sea imprescindible la interpretación, tanto de índole hermenéutica como pragmática. Y esa interpretación tiene que ser susceptible de argumentación, de convencer de su acierto; esto lo obtiene en la retórica, tanto cuando es al interior de un sistema filosófico, como, sobre todo, cuando se trata de dialogar con otro sistema, en la interpretación de sí mismo, del otro, de los textos de uno y otro, y de ese gran texto que es la realidad, objeto de la interpretación ontológica. Es justamente en el juego de las ontologías en el que se necesita más la retórica. Ahora bien, para que no sea una retórica roma y cerrada, ni tampoco desmedidamente abierta, ha de ser analógica, con el esprit de finesse de la atención a la polisemia, pero también con algo del esprit de géometrie que haga que esa polisemia no se pierda en el vacío del sentido ${ }^{20}$.

20 Cf. M. BeUchot, Tratado de hermenéutica analógica, México: UNAM, 1997; el mismo, La retórica como pragmática y hermenéutica, Barcelona: Anthropos, 1998. 